Check for updates

Cite this: Nanoscale Adv., 2019, 1, 1130

\title{
Growth of graphene with large single-crystal domains by Ni foam-assisted structure and its high- gain field-effect transistors $\uparrow$
}

\author{
Xuedong Gao, (D) Cui Yu, ${ }^{\star}$ Zezhao He, Xubo Song, Qingbin Liu, Chuangjie Zhou, \\ Jianchao Guo, Shujun Cai and Zhihong Feng*
}

\begin{abstract}
High-quality graphene materials and high-performance graphene transistors have attracted much attention in recent years. To obtain high-performance graphene transistors, large single-crystal graphene is needed. The synthesis of large-domain-sized single-crystal graphene requires low nucleation density; this can lead to a lower growth rate. In this study, a Ni-foam assisted structure was developed to control the nucleation density and growth rate of graphene by tuning the flow dynamics. Lower nucleation density and high growth rate $\left(\sim 50 \mu \mathrm{m} \mathrm{min}^{-1}\right)$ were achieved with a $4 \mathrm{~mm}$-gap Ni foam. With the graphene transistor fabrication process, a pre-deposited Au film as the protective layer was used during the graphene transfer. Graphene transistors showed good current saturation with drain differential conductance as low as $0.04 \mathrm{~S} \mathrm{~mm}^{-1}$ in the strong saturation region. For the devices with gate length of $2 \mu \mathrm{m}$, the intrinsic cut-off frequency $f_{\mathrm{T}}$ and maximum oscillation frequency $f_{\max }$ were 8.4 and $16.3 \mathrm{GHz}$, respectively, with $f_{\max } / f_{\mathrm{T}}=1.9$ and power gain of up to $6.4 \mathrm{~dB}$ at $1 \mathrm{GHz}$. The electron velocity saturation induced by the surface optical phonons of $\mathrm{SiO}_{2}$ substrates was analyzed. Electron velocity saturation and ultra-thin $\mathrm{Al}_{2} \mathrm{O}_{3}$ gate dielectrics were thought to be the reasons for the good current saturation and high power gain of the graphene transistors.
\end{abstract}

Received 11th September 2018 Accepted 12th December 2018

DOI: $10.1039 / \mathrm{c} 8 \mathrm{na00203g}$

rsc.li/nanoscale-advances oxide, substantially reducing the $\mathrm{CH}_{4}$ percentage, and controlling the channel structure or tube shape..$^{5-9}$ The above methods can effectively increase the size of single-crystal graphene. However, the low nucleation density also leads to a lower growth rate; most growth rates are in the range of $1-10 \mu \mathrm{m} \mathrm{min}^{-1}$, due to which a longer time is required for larger single-crystal graphene growth., ${ }^{5,-12}$

For graphene transistors used in wireless communication circuits, high gain values still hinder the application due to lack of current saturation. ${ }^{13-16}$ The way to obtain current saturation is to open a bandgap by nanopatterning of monolayer graphene (MLG) ${ }^{17}$ or by applying vertical electric displacement on Bernalstacked bilayer graphene (BLG). ${ }^{18,19}$ These methods have their respective drawbacks for practical application. Thinning the gate dielectric is thought to be another efficient way to obtain current saturation. ${ }^{20}$

In this study, we design a simple Ni foam-assisted structure to control the graphene growth on a $\mathrm{Cu}$ foil. With the $\mathrm{Ni}$ foam, the nucleation density and growth kinetics of graphene are controlled. The state of the precursors on the top surface of the $\mathrm{Cu}$ foil is controlled by regulating the gap of the $\mathrm{Ni}$ foam and $\mathrm{Cu}$ foil. With the Ni foam-assisted graphene growth, the nucleation density is lowered to $1 / \mathrm{mm}^{2}$, and the growth rate can be higher than $50 \mu \mathrm{m} \mathrm{min}^{-1}$. A Au film was pre-deposited on the graphene surface as a protective layer to avoid the contamination of graphene during the transfer and FET fabrication process. By 
thinning the gate dielectric $\mathrm{Al}_{2} \mathrm{O}_{3}$ down to $5 \mathrm{~nm}$, graphene FETs with gate length of $2 \mu \mathrm{m}$ show good current saturation and power gain up to $6.4 \mathrm{~dB}$ at $1 \mathrm{GHz}$.

\section{Experimental}

\section{Growth and characterization of graphene}

$\mathrm{Cu}$ foil $\left(98 \%, 25 \mu \mathrm{m}\right.$, Alfa Aesar) was oxidized at $200{ }^{\circ} \mathrm{C}$ for $20 \mathrm{~min}$ on a hot plate. The growth of graphene was conducted in a vertical-type chemical vapor deposition furnace. The $\mathrm{Cu}$ foil was loaded onto the heater, and the pressure was controlled at 25 mbar. Ar gas with a flow of $1000 \mathrm{sccm}$ was used to remove the air, and the temperature was kept at $1000{ }^{\circ} \mathrm{C}$ for $10 \mathrm{~min}$. Then, graphene was grown at $1000{ }^{\circ} \mathrm{C}$ with a methane flow of $2 \mathrm{sccm}$ and $\mathrm{H}_{2}$ flow of $60 \mathrm{sccm}$. The size and nucleation density of graphene were measured by optical microscopy (OM). The $\mathrm{Cu}$ foil with graphene was oxidized at $160{ }^{\circ} \mathrm{C}$ for $10 \mathrm{~min}$ on a hot plate to increase the contrast for OM observation. Micro-Raman scattering experiments were performed at RT with a spectrometer $(514 \mathrm{~nm})$.

\section{Graphene transfer}

After the growth of graphene on the $\mathrm{Cu}$ foil, $30 \mathrm{~nm}$ of $\mathrm{Au}$ film was immediately deposited onto the graphene surface on the top side of the $\mathrm{Cu}$ foil. The graphene on the bottom side of $\mathrm{Cu}$ foil was removed by $\mathrm{O}_{2}$ plasma. $\mathrm{Cu}$ foil was etched by $\mathrm{FeCl}_{3}$ aqueous solution and then, the $\mathrm{Au} /$ graphene film was rinsed in deionized water three times. Au/graphene was transferred onto an $\mathrm{SiO}_{2} / \mathrm{Si}$ wafer; the thickness of $\mathrm{SiO}_{2}$ was $90 \mathrm{~nm}$. Au/graphene/ $\mathrm{SiO}_{2} / \mathrm{Si}$ was dried at $90{ }^{\circ} \mathrm{C}$ for $20 \mathrm{~min}$.

\section{Device fabrication}

Graphene FETs were fabricated by a self-aligned process following the method reported in our previous study. ${ }^{21}$ Optical lithography was adopted to define the channel regions, followed by electrical isolation by exposing the graphene surface to oxygen plasma after removal of the Au film outside the channel. We deposited Ti $20 \mathrm{~nm} / \mathrm{Pt} 50 \mathrm{~nm} / \mathrm{Au} 150 \mathrm{~nm}$ to form the electrode pads. Gates of $2 \mu \mathrm{m}$ were patterned by optical lithography. Subsequently, the Au layer under the gates was wet-etched to form a self-aligned source and drain ohmic contacts automatically. Next, $1.7 \mathrm{~nm}$-thick $\mathrm{Al}$ was deposited by e-beam evaporation, which was then oxidised in air for 1 day at room temperature to form an $\mathrm{Al}_{2} \mathrm{O}_{3}$ dielectric. The thickness of the alumina was $t_{\mathrm{Al}_{2} \mathrm{O}_{3}} \approx 5 \mathrm{~nm}$. Finally, a $150 \mathrm{~nm}$-thick Al metal film was evaporated to form the gate electrodes.

\section{Results and discussion}

$\mathrm{Ni}$ foam is used to assist the graphene growth by controlling the precursor flow dynamics. Fig. 1(a) shows the schematic of $\mathrm{Ni}$ foam-assisted graphene growth. The distance between the $\mathrm{Ni}$ foam and $\mathrm{Cu}$ substrate is $4 \mathrm{~mm}$. The flow rate of the precursors decreases due to the $\mathrm{Ni}$ foam on the top of the $\mathrm{Cu}$ substrate; the decreased flow rate can lead to lower nucleation density and a higher growth rate, as shown in Fig. 1(c), with a growth time of

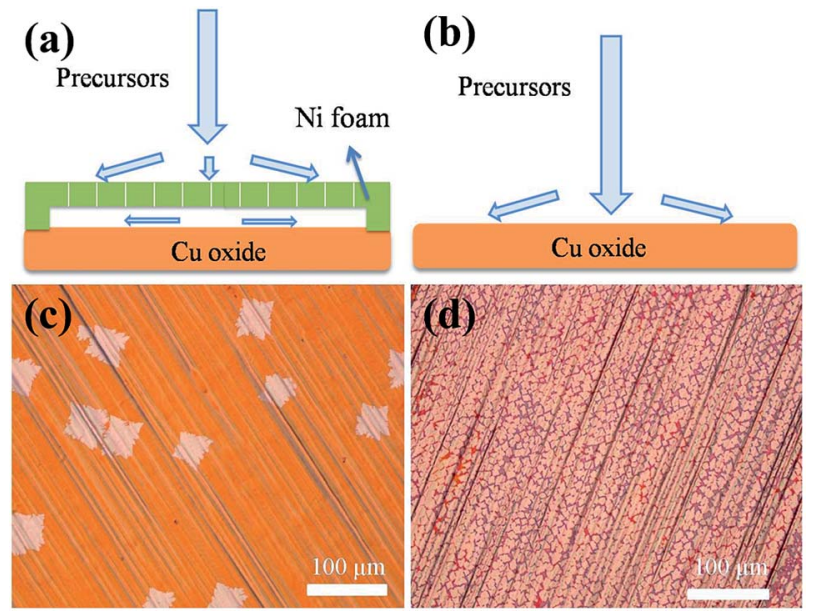

Fig. 1 (a) Schematic image and (c) OM image of Ni foam-assisted graphene growth with a growth time of 15 min; (b) schematic image and (d) OM image of conventional graphene growth on $\mathrm{Cu}$ foil with a growth time of $10 \mathrm{~min}$.

$15 \mathrm{~min}$. The schematic without $\mathrm{Ni}$ foam-assisted graphene growth is shown in Fig. 1(b). Fig. 1(d) shows the results without Ni foam-assisted growth. The growth time is 10 min. Fig. 1(d) shows very high nucleation density and slower growth rate compared with Fig. 1(c), demonstrating that we can decrease the nucleation density and increase the growth rate with the $\mathrm{Ni}$ foam-assisted graphene growth process.

The mechanism of the influence of $\mathrm{Ni}$ foam in the graphene growth process was studied. The $\mathrm{Cu}$ foil was oxidized before insertion into the tube, and we used EDX to study the oxygen coverage on the $\mathrm{Cu}$ foil. SEM and EDX images are shown in Fig. S1. $\dagger$ After heating to $1030^{\circ} \mathrm{C}$ under Ar gas for $10 \mathrm{~min}$, the oxygen coverage of the $\mathrm{Cu}$ foil surface with the $\mathrm{Ni}$ foam structure was significantly higher than that without the Ni foam-assisted structure. With the Ni foam structure, the surface oxygen coverage was at $4.62 \%$, and without the $\mathrm{Ni}$ foam structure, the surface oxygen coverage was at $1.28 \%$. The higher oxygen content can suppress the nucleation and improve the graphene growth rate. ${ }^{22}$

To study the effect of the precursor flow rate, graphene growth under different gaps between the $\mathrm{Ni}$ foam and $\mathrm{Cu}$ substrate is studied. The gaps are set as $3 \mathrm{~mm}, 4 \mathrm{~mm}$, and 5 $\mathrm{mm}$. The growth times of graphene with and without $\mathrm{Ni}$ foam are $15 \mathrm{~min}$ and $10 \mathrm{~min}$, respectively. Fig. 2(a), (b) and (c) show the graphene growth with $3 \mathrm{~mm}, 4 \mathrm{~mm}$, and $5 \mathrm{~mm}$ gaps, respectively. It can be found that the nucleation density increases as the gap increases. Fig. 2(d) shows the graphene grown without $\mathrm{Ni}$ foam; the nucleation density is very high $\left(\sim 1.2 \times 10^{4} / \mathrm{mm}^{2}\right)$ and the graphene size is very small. Fig. $2(\mathrm{e})$ shows the corresponding nucleation density of the Ni foamassisted graphene growth with different gaps. As the Ni foam gap increases, the precursor flow rate increases, resulting in higher nucleation density. Fig. 2(f) shows the average growth rate of graphene with different gaps. The rate of graphene growth is the highest in the $4 \mathrm{~mm} \mathrm{Ni}$ foam gap. Without $\mathrm{Ni}$ foam, the graphene growth has very high precursor flow rate but 

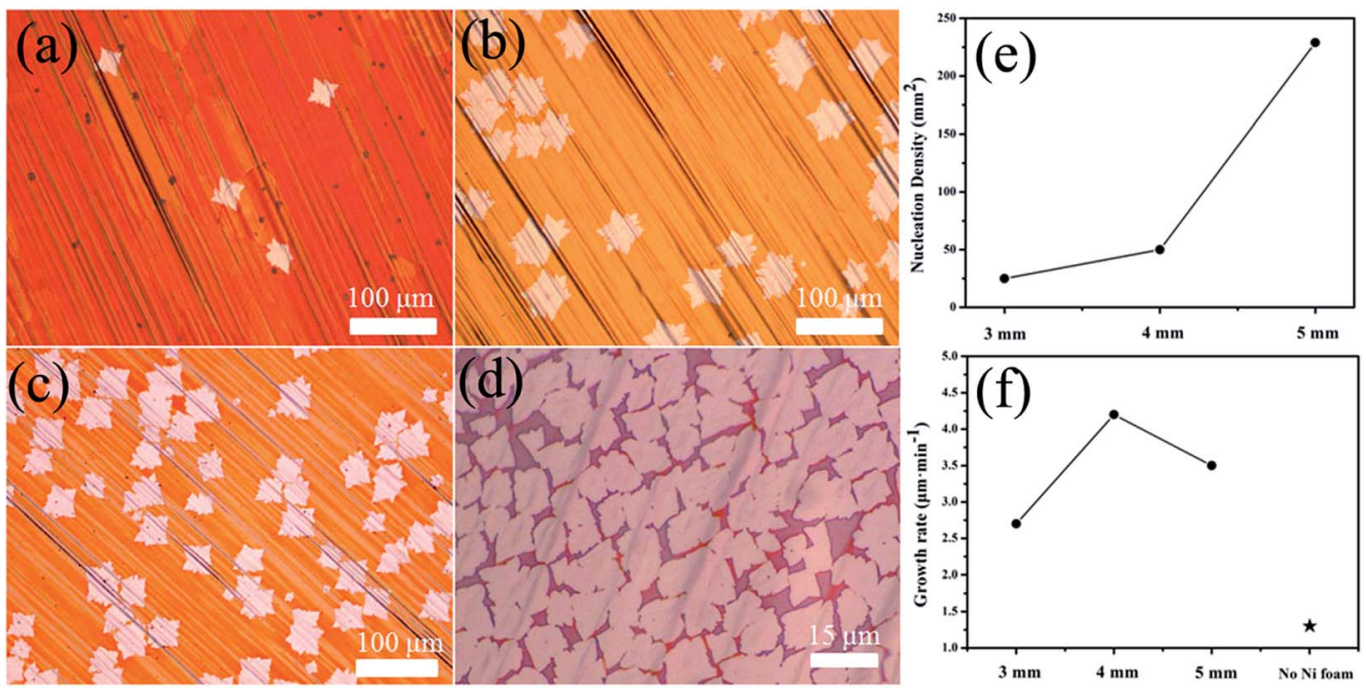

Fig. 2 Graphene growth under different gaps between the Ni foam and Cu substrate. Gap size: (a) 3 mm, (b) 4 mm, and (c) 5 mm. (d) Graphene growth without the Ni foam. (e) Nucleation density. (f) Growth rate of graphene with different Ni foam gaps.

a lower growth rate. The above results show that $4 \mathrm{~mm} \mathrm{Ni}$ foam gap is appropriate for assisted graphene growth; it can maintain a higher growth rate and a relatively lower nucleation density.

Fig. 3 shows the images of graphene growth with Ni foam (4 mm gap) and without $\mathrm{Ni}$ foam at $1060^{\circ} \mathrm{C}$. For graphene with $\mathrm{Ni}$ foam grown at $1060^{\circ} \mathrm{C}$ for $10 \mathrm{~min}$, the grain size of graphene is about $512 \mu \mathrm{m}$, as shown in Fig. 3(a). The nucleation density is $\sim 1 / \mathrm{mm}^{2}$ and growth rate is $\sim 51.2 \mu \mathrm{m} \mathrm{min}{ }^{-1}$. With prolonged growth time, the grain size of graphene reaches millimeter scale. Fig. 3(b) shows graphene grown for $1 \mathrm{~min}$ without $\mathrm{Ni}$ foam at $1060{ }^{\circ} \mathrm{C}$. The nucleation density shows no decrease as the growth temperature increases to $1060{ }^{\circ} \mathrm{C}$. Fig. 3(c) and (d) show the OM images of the transferred graphene onto $\mathrm{SiO}_{2} / \mathrm{Si}$ substrates. Fig. 3(c) shows the image of graphene growth with $\mathrm{Ni}$ foam. The surface of graphene in optical microscopy view is very clear. There are many adlayers for graphene grown without $\mathrm{Ni}$ foam, as shown in Fig. 3(d). This is mainly due to the large number of boundaries between the small grains. Precursors go through to the boundary, forming many adlayers. Fig. 3(e) and (f) show the Raman shift of transferred graphene on the $\mathrm{SiO}_{2} / \mathrm{Si}$ substrates. As shown in Fig. 3(e), for graphene grown with $\mathrm{Ni}$ foam, the intensity ratio of the $2 \mathrm{D} / \mathrm{G}$ peak is 3.4 with no clear $\mathrm{D}$ peak, demonstrating a single-layer graphene of high-quality. ${ }^{23}$ For graphene grown without Ni foam, the Raman shifts of the single-
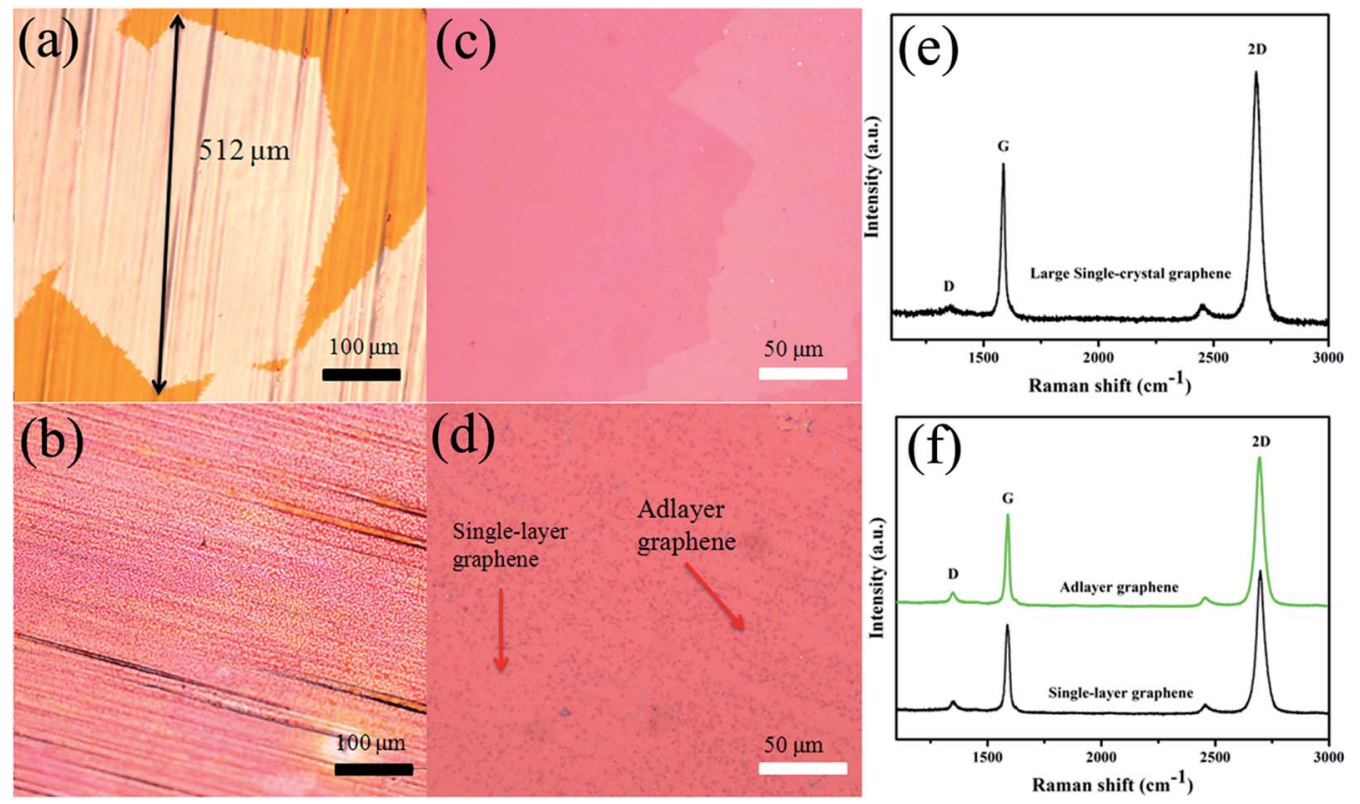

Fig. 3 OM images of graphene growth on Cu foil (a) with Ni foam ( $4 \mathrm{~mm}$ gap) and (b) without Ni foam at $1060^{\circ} \mathrm{C}$. OM images and Raman pattern of graphene transferred to the $\mathrm{SiO}_{2} / \mathrm{Si}$ substrates: (c, e) with $\mathrm{Ni}$ foam (4 mm gap) and (d, f) without Ni foam. 
layer and adlayers (in Fig. 3(d)) are given in Fig. 3(f). The intensity ratio of the $2 \mathrm{D} / \mathrm{G}$ peak is 3.5 for the adlayer graphene, demonstrating that adlayers do not exhibit an $\mathrm{AB}$ stacking structure. ${ }^{24}$ The relative intensity of the D/G peak in Fig. 3(f) is higher than that in Fig. 3(e), demonstrating that the quality of graphene grown with $\mathrm{Ni}$ foam is higher than that without $\mathrm{Ni}$ foam. ${ }^{23}$

The relationship between the growth rate and material quality was studied. We set up five sets of experiments. The first experiment involved the fabrication of a $\mathrm{Cu}$ foil without a $\mathrm{Ni}$ foamassisted structure with growth temperature of $1000{ }^{\circ} \mathrm{C}$; the other experiments involved the fabrication of $\mathrm{Cu}$ foils with $4 \mathrm{~mm}$-gap $\mathrm{Ni}$ foam with growth temperatures of $1000{ }^{\circ} \mathrm{C}, 1020{ }^{\circ} \mathrm{C}, 1040{ }^{\circ} \mathrm{C}$ and $1060{ }^{\circ} \mathrm{C}$. The graphene growth rates in these five samples are found to be $\sim 1 \mu \mathrm{m} \mathrm{min}{ }^{-1}, \sim 4 \mu \mathrm{m} \mathrm{min}^{-1}, \sim 12 \mu \mathrm{m} \min ^{-1}, \sim 23$ $\mu \mathrm{m} \mathrm{min}{ }^{-1}$ and $\sim 50 \mu \mathrm{m} \mathrm{min}{ }^{-1}$. The Raman shifts of these five graphene samples were also studied. The Raman results are shown in Fig. S2. $\dagger$ The FWHM values of the 2D peaks of the five samples are $38 \mathrm{~cm}^{-1}, 37 \mathrm{~cm}^{-1}, 39 \mathrm{~cm}^{-1}, 38 \mathrm{~cm}^{-1}$ and $43 \mathrm{~cm}^{-1}$, showing that the samples are all monolayer graphene. It was also found that the $I_{\mathrm{D}} / I_{\mathrm{G}}$ ratios decrease as the growth rates increase. The $I_{\mathrm{D}} / I_{\mathrm{G}}$ ratios of the five samples are $0.05,0.03,0.03,0.02$ and 0.02 . The larger $I_{\mathrm{D}} / I_{\mathrm{G}}$ ratio of the graphene sample with a growth rate of $\sim 1 \mu \mathrm{m} \mathrm{min}{ }^{-1}$ may be mainly due to the small single-crystal size and numerous grain boundaries.

The fabrication schedule and OM image of graphene FETs fabricated by a self-aligned process are shown in Fig. S3. $\dagger$ Dualgate graphene transistors with gate length of $2 \mu \mathrm{m}$ and gate width of $100 \mu \mathrm{m} \times 2$ were fabricated. The field-effect mobility values of the graphene transistors were $2450 \mathrm{~cm}^{2} \mathrm{~V}^{-1} \mathrm{~s}^{-1}$ (hole) and $3307 \mathrm{~cm}^{2} \mathrm{~V}^{-1} \mathrm{~s}^{-1}$ (electron), respectively (Fig. 4(d)), indicating the high quality of the graphene material and less contamination in the device fabrication process.

Fig. 4 shows the DC electrical transport characteristics of graphene FETs. The DC electrical transport measurements were obtained using a Semiconductor Parameter Analyser (SPA). As shown in Fig. 4(a), the drain current $\left(I_{\mathrm{ds}}\right)$ shows strong saturation with maximum scaled on-current $I_{\mathrm{ds}}$ reaching $0.54 \mathrm{~A}$ $\mathrm{mm}^{-1}$. The sample shows n-type doping with the Dirac point at $V_{\mathrm{gs}}=-0.85 \mathrm{~V}$ and the maximum transconductance $\left(g_{\mathrm{m}}\right)$ is measured at $V_{\mathrm{ds}}=-2 \mathrm{~V}$ is $0.2 \mathrm{~S} \mathrm{~mm}^{-1}$, as shown in Fig. 4(b). Due to the strong drain current saturation, the drain differential conductance $\left(g_{\mathrm{ds}}\right)$ is small, as shown in Fig. $4(\mathrm{c})$. The $g_{\mathrm{ds}}$ value is as low as $0.04 \mathrm{~S} \mathrm{~mm}^{-1}$ in the strong saturation region $(-2 \mathrm{~V} \leq$ $\left.V_{\mathrm{ds}} \leq-3 \mathrm{~V}\right)$.

High-frequency scattering parameters ( $S$-parameters) of the transistors were measured up to $10 \mathrm{GHz}$ using standard GSG probes. Fig. 5(a)-(c) show the as-measured, de-embedded, and intrinsic short-circuit current gain $\left(\left|H_{21}\right|^{2}\right)$, maximum stable/ available gain (MSG/MAG), and Mason's unilateral power gain $(U)$ extracted from $S$-parameters for the graphene transistor with $L_{\mathrm{g}}=2 \mu \mathrm{m}$ and $W_{\mathrm{g}}=100 \mu \mathrm{m} \times 2$. As a result, the intrinsic cut-off frequency $f_{\mathrm{T}}$ and maximum oscillation frequency $f_{\max }$ were determined to be 8.4 and $16.3 \mathrm{GHz}$ for the device. The calculated $f_{\max }$ values from the maximum stable/available gain (MSG/MAG) and Mason's unilateral power gain $(U)$ showed good consistency with each other, indicating the veracity of the derivation process.
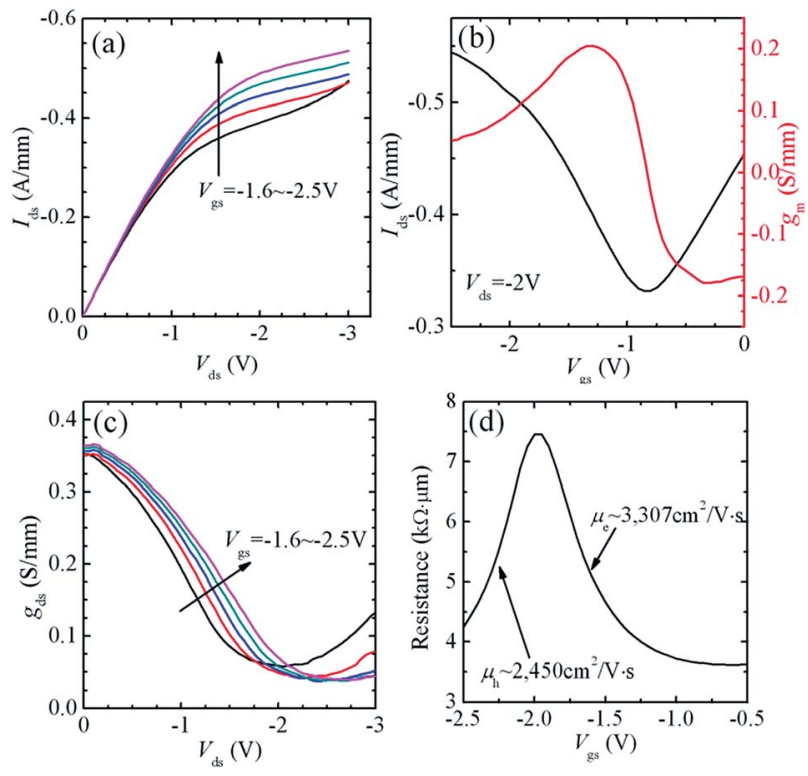

Fig. 4 DC characteristics of the graphene transistors. (a) The currentvoltage characteristics at gate voltages ranging from $-1.6 \mathrm{~V}$ to $-2.5 \mathrm{~V}$. (b) Transfer characteristics at $V_{\mathrm{ds}}=-2 \mathrm{~V}$ with $-2.5 \mathrm{~V} \leq \mathrm{V}_{\mathrm{gs}} \leq 0 \mathrm{~V}$. (c) Drain differential conductance $g_{\text {ds. }}$ (d) Scaled resistance of a graphene transistor versus gate voltage at $V_{\mathrm{ds}}=-0.1 \mathrm{~V}$.

Fig. 5(d) shows forward power gain $\left|S_{21}\right|$ and the AC opencircuit voltage gain $Z_{21} / Z_{11}$ as a function of frequency for the graphene transistor. The AC open-circuit voltage gain reaches $15 \mathrm{~dB}$
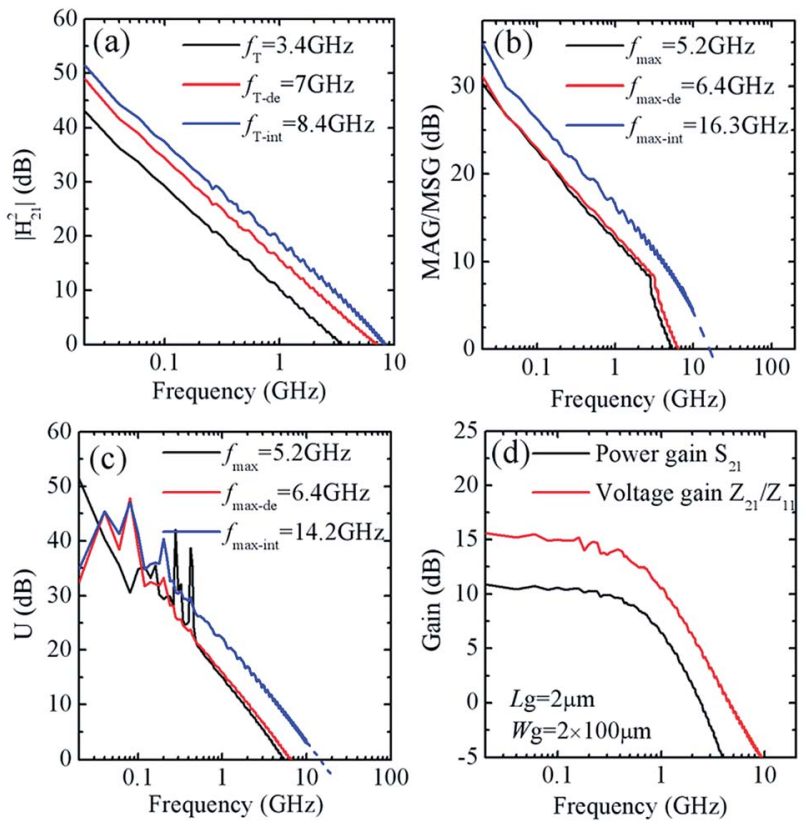

Fig. 5 High-frequency characteristics of the GFET with a gate length of $2 \mu \mathrm{m}$ and a gate width of $100 \mu \mathrm{m} \times 2$. (a) Measured, de-embedded, and intrinsic $\left|H_{21}\right|^{2}$; (b) measured, de-embedded, and intrinsic maximum stable/available gain (MSG/MAG); (c) measured, deembedded, and intrinsic Mason's unilateral power gain (U); and (d) measured frequency response of $A C$ open-circuit voltage gain $\left(Z_{21}\right)$ $\left.Z_{11}\right)$ and forward power gain $\left(\left|S_{21}\right|\right)$. 
Table 1 Component parameters of the graphene transistor with gate length of $2 \mu \mathrm{m}$ and gate width of $100 \mu \mathrm{m} \times 2$

\begin{tabular}{llllllll}
\hline$C_{\mathrm{gd}}(\mathrm{fF})$ & $C_{\mathrm{gs}}(\mathrm{fF})$ & $C_{\mathrm{ds}}(\mathrm{fF})$ & $g_{\mathrm{ds}}(\mathrm{mS})$ & $g_{\mathrm{m}}(\mathrm{mS})$ & $R_{\mathrm{i}}(\Omega)$ & $R_{\mathrm{g}}(\Omega)$ & $R_{\mathrm{S}}(\Omega)$ \\
\hline 341 & 1407 & 785 & 17 & 96 & 3.2 & 5 & $R_{\mathrm{d}}(\Omega)$ \\
\hline & 140 & 6.5 & 6.5
\end{tabular}

for the measured frequency range. Power gain $\left|S_{21}\right|$, which reflects the real power amplification of a two-port network, is around 6.4 $\mathrm{dB}$ at $1 \mathrm{GHz}$ for the device, which is among the highest reported values for CVD graphene transistors. ${ }^{25,26}$ The graphene FETs show very high power gain, which is a result of the strong drain current saturation-induced low drain differential conductance $\left(g_{\mathrm{ds}}\right)$.

There are two possible reasons for the strong drain current saturation. One is the electron velocity saturation induced by the surface optical phonons of $\mathrm{SiO}_{2}$ substrates. ${ }^{27,28}$ In the case of graphene with mobility limited by impurity scattering, the high field behavior is determined by the emission of surface optical phonons in the $\mathrm{SiO}_{2}$ substrate. ${ }^{29}$ The energy of the surface optical phonons of $\mathrm{SiO}_{2}$ is $\varepsilon_{\mathrm{SO}} \approx 59 \mathrm{meV}$. From $\varepsilon_{\mathrm{SO}}$, the saturated electron velocity $v_{\text {sat }}$ can be estimated via emission of the surface optical phonons, which is denoted as follows: $:^{30,31}$

$$
v_{\mathrm{sat}}=\frac{2}{\hbar} \frac{\varepsilon_{\mathrm{SO}}}{\pi \sqrt{\pi n_{\mathrm{s}}}} \sqrt{1-\frac{\varepsilon_{\mathrm{SO}}^{2}}{4 \pi n_{\mathrm{s}}\left(\hbar v_{\mathrm{f}}\right)^{2}}} \frac{1}{N_{\mathrm{OP}}+1}
$$

here, $N_{\mathrm{OP}}$ is the phonon occupation number. In the high carrier density limit, the above relation may be reduced to

$$
v_{\mathrm{sat}}=\frac{2 \varepsilon_{\mathrm{SO}}}{\hbar \pi \sqrt{\pi n_{\mathrm{s}}}}
$$

Table 1 shows the small signal model parameters of GFET. $^{32-34}$ The extracted gate capacitance $C_{\mathrm{g}}=C_{\mathrm{gs}}+C_{\mathrm{gd}}$ is 1748 $\mathrm{fF}$. The sheet density of the graphene channel can be estimated by $n_{\mathrm{s}}=V_{\text {Dirac }} \times C_{\mathrm{g}} / e .^{35}$ The sample shows n-type doping with the Dirac point at $V_{\mathrm{gs}}=-0.85 \mathrm{~V}$, and the calculated graphene channel $\left(n_{\mathrm{s}}\right)$ is $2.3 \times 10^{12} \mathrm{~cm}^{-2}$. From eqn (2), one can expect saturated electron velocity of $1.5 \times 10^{7} \mathrm{~cm} \mathrm{~s}^{-1}$ with $n_{\mathrm{s}}=2.3 \times$ $10^{12} / \mathrm{cm}^{-2}$ in the graphene on $\mathrm{Si} / \mathrm{SiO}_{2}$ substrates. The intrinsic cut-off frequency $f_{\mathrm{T}}$ in an FET can be estimated as follows:

$$
f_{\mathrm{T}}=\frac{v_{\mathrm{sat}}}{2 \pi L_{\mathrm{g}}}
$$

For a graphene transistor with gate length $L_{\mathrm{g}}$ of $2 \mu \mathrm{m}$, the estimated intrinsic cut-off frequency $f_{\mathrm{T}}$ is $12 \mathrm{GHz}$ for $n_{\mathrm{sh}}$ of $2.3 \times$ $10^{12} \mathrm{~cm}^{-2}$. The measured intrinsic $f_{\mathrm{T}}$ of our device is $8.4 \mathrm{GHz}$, which is slightly lower than the estimated one, indicating that the electron velocity can achieve saturation. The ultra-thin selfoxidized $\mathrm{AlO}_{x}$ gate dielectric should also be helpful in drain current saturation. Han et al. have shown that the low-density state (DOS) of graphene can help obtain drain current saturated characteristics in thin dielectric devices. ${ }^{20}$ They demonstrated that by employing a very thin gate dielectric (equivalent oxide thickness (EOT) less than $2 \mathrm{~nm}$ ), full drain current saturation can be obtained for graphene FETs with short channels. EOT of graphene FETs in this study is approximately $2 \mathrm{~nm}$, which will be beneficial for current saturation.

\section{Conclusions}

With a $\mathrm{Ni}$ foam-assisted structure to control the graphene growth on a $\mathrm{Cu}$ foil, graphene with grain size of millimeters was prepared. A pre-deposited Au film as a protective layer to avoid the pollution of graphene was used during the transfer and graphene FET fabrication process. Graphene FETs with gate length of $2 \mu \mathrm{m}$ show good current saturation and power gain up to $6.4 \mathrm{~dB}$ at $1 \mathrm{GHz}$. Electron velocity saturation induced by surface optical phonons of $\mathrm{SiO}_{2}$ substrates and ultra-thin gate dielectric were thought to be the reasons for good current saturation and high power gain. Graphene transistors with short gate length will be developed in the next study to push frequency and power gain.

\section{Conflicts of interest}

There are no conflicts to declare.

\section{Acknowledgements}

This work was supported by the National Natural Science Foundation of China (61674131 and 61306006) and Basic Research Program of Hebei (18961020D).

\section{Notes and references}

1 Z. Guoke, X. Li, M. Huang, Z. Zhen, Y. Zhong, Q. Chen, X. Zhao, Y. He, R. Hu, T. Yang, et al. The Physics and Chemistry of Graphene-on-Surfaces, Chem. Soc. Rev., 2017, 46, 4417-4449.

2 A. H. Castro Neto, N. M. R. Peres, K. S. Novoselov and A. K. Geim, The physics of heavy $Z^{\prime}$ gauge bosons, Rev. Mod. Phys., 2009, 81, 1199-1228.

3 Z. Hailong, W. Jong Yu, L. Liu, R. Cheng, Y. Chen, X. Huang, Y. Liu, Y. Wang, Y. Huang and X. Duan, Chemical Vapour Deposition Growth of Large Single Crystals of Monolayer and Bilayer Graphene, Nat. Commun., 2013, 4, 2096.

4 W. Huan, X. Xu, J. Li, L. Lin, L. Sun, X. Sun, S. Zhao, C. Tan, C. Chen, W. Dang, et al. Surface Monocrystallization of Copper Foil for Fast Growth of Large Single-Crystal Graphene under Free Molecular Flow, Adv. Mater., 2016, 28, 8968-8974.

5 C. Ren-Jie, C.-H. Lee, M.-K. Lee, C.-W. Chen and C.-Y. Wen, Effects of Surface Oxidation of $\mathrm{Cu}$ Substrates on the Growth Kinetics of Graphene by Chemical Vapor Deposition, Nanoscale, 2017, 9, 2324-2329.

6 Y. Zheng, J. Lin, Z. Peng, Z. Sun, Y. Zhu, L. Li, C. Xiang, E. Loic Samuel, C. Kittrell and J. M. Tour, Toward the Synthesis of Wafer-Scale Single-Crystal Graphene on Copper Foils, ACS Nano, 2012, 6, 9110-9117. 
7 W. Ruizhe, J. Pan, X. Ou, Q. Zhang, Y. Ding, P. Sheng and Z. Luo, Concurrent Fast Growth of Sub-Centimeter SingleCrystal Graphene with Controlled Nucleation Density in a Confined Channel, Nanoscale, 2017, 9, 9631-9640.

8 L. Xuesong, C. W. Magnuson, A. Venugopal, R. M. Tromp, J. B. Hannon, E. M. Vogel, L. Colombo and R. S. Ruoff, Large-Area Graphene Single Crystals Grown by LowPressure Chemical Vapor Deposition of Methane on Copper, J. Am. Chem. Soc., 2011, 133, 2816-2819.

9 C. Shanshan, H. Ji, H. Chou, Q. Li, H. Li, J. Won Suk, R. Piner, L. Liao, W. Cai and R. S. Ruoff, Millimeter-Size Single-Crystal Graphene by Suppressing Evaporative Loss of $\mathrm{Cu}$ During Low Pressure Chemical Vapor Deposition, Adv. Mater., 2013, 25, 2062-2065.

10 L. Xuesong, W. Cai, J. An, S. Kim, J. Nah, D. Yang, R. Piner, A. Velamakanni, I. Jung, E. Tutuc, et al. Large-Area Synthesis of High-Quality and Uniform Graphene Films on Copper Foils, Science, 2009, 324, 1312-1314.

11 J. Li, X. Y. Wang, X. R. Liu, Z. Jin, D. Wang and L. J. Wan, Facile growth of centimeter-sized single-crystal graphene on copper foil at atmospheric pressure, J. Mater. Chem. C, 2015, 3, 3530-3535.

12 H. Yufeng, M. S. Bharathi, L. Wang, Y. Liu, H. Chen, S. Nie, X. Wang, H. Chou, C. Tan, B. Fallahazad, et al. The Role of Surface Oxygen in the Growth of Large Single-Crystal Graphene on Copper, Science, 2013, 342, 720-723.

13 L. Liao, J. Bai, R. Cheng, H. Zhou, L. Liu, Y. Liu, Y. Huang and X. F. Duan, Scalable Fabrication of Self-Aligned Graphene Transistors and Circuits on Glass, Nano Lett., 2012, 12, 2653-2657.

14 Y. Wu, K. A. Jenkins, A. Valdes-Garcia, D. B. Farmer, Y. Zhu, A. A. Bol, C. Dimitrakopoulos, W. Zhu, F. Xia, P. Avouris and Y. M. Lin, State-of-the-Art Graphene High-Frequency Electronics, Nano Lett., 2012, 12, 3062-3067.

15 S. Vaziri, A. D. Smith, M. Ostling, G. Lupina, J. Dabrowski, G. Lippert, W. Mehr, F. Driussi, S. Venica, V. Di Lecce, et al. Going Ballistic: Graphene Hot Electron Transistors, Solid State Commun., 2015, 224, 64-75.

16 G. Filippo, G. Greco, F. Roccaforte and S. Sonde, Vertical Transistors Based on 2D Materials: Status and Prospects, Crystals, 2018, 8(2), 70.

17 X. Li, X. Wang, L. Zhang, S. Lee and H. Dai, Chemically derived, ultrasmooth graphene nanoribbon semiconductors, Science, 2008, 319, 1229-1232.

18 T. Ohta, A. Bostwick, T. Seyller, K. Horn and E. Rotenberg, Controlling the electronic structure of bilayer graphene, Science, 2006, 313, 951-954.

19 B. N. Szafranek, G. Fiori, D. Schall, D. Neumaier and H. Kurz, Current Saturation and Voltage Gain in Bilayer Graphene Field Effect Transistors, Nano Lett., 2012, 12, 1324-1328.

20 S. J. Han, D. Reddy, G. D. Carpenter, A. D. Franklin and K. A. Jenkins, Current Saturation in Submicrometer Graphene Transistors with Thin Gate Dielectric: Experiment, Simulation, and Theory, ACS Nano, 2012, 6, 5220-5226.

21 Z. H. Feng, C. Yu, J. Li, Q. B. Liu, Z. Z. He, X. B. Song, J. J. Wang and S. J. Cai, An Ultra Clean Self-Aligned
Process for High Maximum Oscillation Frequency Graphene Transistors, Carbon, 2014, 75, 249-254.

22 Z. Zhihong, X. Xu, L. Qiu, S. Wang, T. Wu, F. Ding, H. Peng and K. Liu, The Way towards Ultrafast Growth of SingleCrystal Graphene on Copper, Adv. Sci., 2017, 4(9), 1700087.

23 A. C. Ferrari, Raman spectroscopy of graphene and graphite: Disorder, electron-phonon coupling, doping and nonadiabatic effects, Solid State Commun., 2007, 143, 47-57.

24 Z. H. Ni, H. M. Wang, J. Kasim, H. M. Fan, T. Yu, Y. H. Wu, Y. P. Feng and Z. X. Shen, Graphene Thickness Determination Using Reflection and Contrast Spectroscopy, Nano Lett., 2007, 9, 2758-2763.

25 M. Tian, X. Li, T. Li, Q. Gao, X. Xiong, Q. Hu, M. Wang, $\mathrm{X}$. Wang and $\mathrm{Y}$. Wu, High-Performance CVD BernalStacked Bilayer Graphene Transistors for Amplifying and Mixing Signals at High Frequencies, ACS Appl. Mater. Interfaces, 2018, 10, 20219-20224.

26 E. Guerriero, P. Pedrinazzi, A. Mansouri, O. Habibpour, M. Winters, N. Rorsman, A. Behnam, E. A. Carrion, A. Pesquera, A. Centeno, A. Zurutuza, E. Pop, H. Zirath and R. Sordan, High-Gain Graphene Transistors with a Thin $\mathrm{AlO}_{x}$ Top-Gate Oxide, Sci. Rep., 2017, 7, 2419.

27 C. R. Dean, A. F. Young, I. Meric, C. Lee, L. Wang, S. Sorgenfrei, K. Watanabe, T. Taniguchi, P. Kim, K. L. Shepard, et al. Boron Nitride Substrates for HighQuality Graphene Electronics, Nat. Nanotechnol., 2010, 5(10), 722-726.

28 G. Filippo, S. Sonde, R. Lo Nigro, E. Rimini and V. Raineri, Mapping the Density of Scattering Centers Limiting the Electron Mean Free Path in Graphene, Nano Lett., 2011, 11(11), 4612-4618.

29 J. H. Chen, C. Jang, S. Xiao, M. Ishigami and M. S. Fuhrer, Electronic properties and devices intrinsic and extrinsic performance limits of graphene devices on $\mathrm{SiO}_{2}$, Nat. Nanotechnol., 2008, 3, 206-209.

30 V. E. Dorgan, M. H. Bae and E. Pop, Mobility and saturation velocity in graphene on $\mathrm{SiO}_{2}$, Appl. Phys. Lett., 2010, 97, 082112.

31 M. Inanc, M. Han, A. Yound, B. Ozyilmaz, P. Kim and K. Shepard, Current saturation in zero-bandgap, top-gated graphene, Nat. Nanotechnol., 2008, 3, 654-659.

32 C. Yu, Z. Z. He, J. Li, X. B. Song, Q. B. Liu, S. J. Cai and Z. H. Feng, Quasi-free-standing bilayer epitaxial graphene field-effect transistors on $4 \mathrm{H}-\mathrm{SiC}$ (0001) substrates, Appl. Phys. Lett., 2016, 108, 016602.

33 J. S. Moon, D. Curtis, M. Hu, D. Wong, C. MsGuire, P. M. Campbell, G. Jernigan, J. L. Tedesco, B. Vanmil, R. Myers-Ward, C. Eddy and D. K. Gaskill, Epitaxial graphene FETs on Si-face $6 \mathrm{H}$-SiC substrate, IEEE Electron Device Lett., 2009, 30, 650-652.

34 J. S. Moon, et al., Graphene FETs for zero-bias linear resistive FET mixers, IEEE Electron Device Lett., 2013, 34, 465-467.

35 K. S. Novoselov, A. K. Geim, S. V. Morozov, D. Jiang, Y. Zhang, S. V. Dubonos, I. V. Grigorieva and A. A. Firsov, Electric field effect in atomically thin carbon films, Science, 2004, 306, 666-669. 